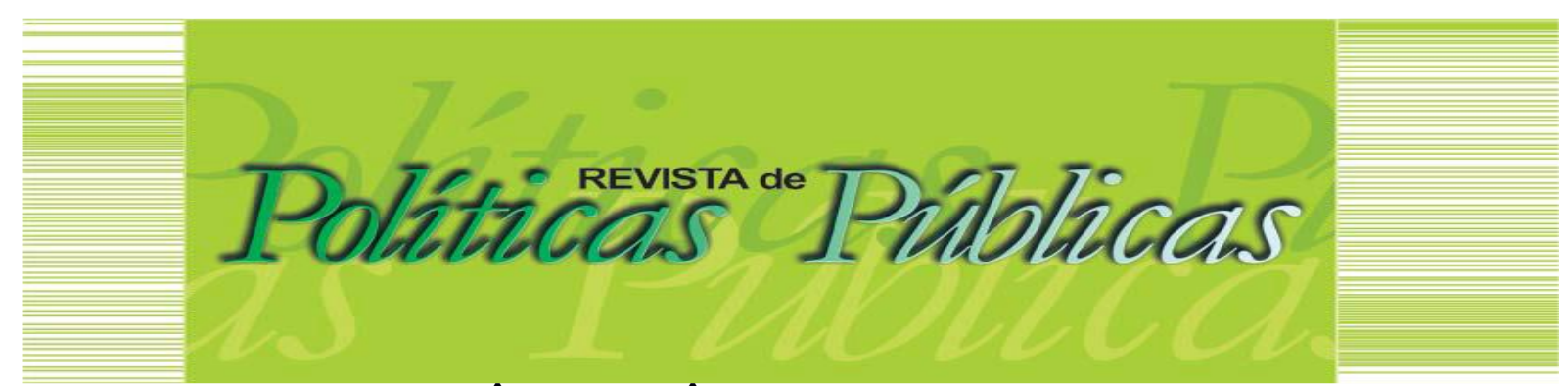

\title{
AGRAVAMENTO DA VIOLÊNCIA DE GÊNERO NO CONTEXTO DA PANDEMIA DA Covid-19
}

\author{
Aline Martins Mesquita1 \\ Anna Júlia Giurizatto Medeiros² \\ Elvira Simões Barretto ${ }^{3}$ \\ Jerônimo da Silva ${ }^{4}$
}

\section{Resumo}

Este trabalho realiza uma reflexão sobre o agravamento da violência de gênero em tempo de pandemia da Covid-19, com uma abordagem em âmbito nacional e internacional. Partindo de uma pesquisa bibliográfica, propõe uma narrativa que se encadeia a partir de elos de compreensão de que raízes da cultura da violência em sociedades capitalistas ocidentais,se retroalimentam para dar suporte à manutenção da ordem burguesa moderna, com parâmetros em um modelo referencial de organização androcêntrico. Esta pesquisarefuta as interpretações equivocadas acerca da pandemia como responsável pelo aumento do fenômeno da violência de gênero, pois tal afirmativa nega a historicidade da violência de gênero. Defende, ainda,que a promoção de autonomia das mulheres, não somente do ponto de vista material, é de suma importância para o enfrentamento da violência de gênero.

Palavras-chave: Violência de gênero. Pandemia. Covid-19. Brasil. Mundo

\section{AGGRAVATION OF GENDER VIOLENCE IN THE CONTEXT OF THE Covid-19 PANDEMIC}

\begin{abstract}
This work reflects on the aggravation of gender violence in the time of the Covid-19 pandemic, with a national and international approach. Based on a bibliographic research, a narrative is proposed defending the perception that the roots of the culture of violence in Western capitalist societies support the maintenance of the modern bourgeois order, with parameters in a referential model of androcentric organization. In this research, the misinterpretations about the pandemic as being responsible for the increase in the phenomenon of gender violence are refuted, as this statement denies the historicity of gender violence. It is argued that the promotion of women's autonomy, not only from a material point of view, is of paramount importance for fighting gender-based violence.
\end{abstract}

Keywords: Gender violence, Pandemic, Covid-19, Brazil, World

Artigo recebido em: 21/12/2020 Aprovado em: 20/05/2021

DOI: http://dx.doi.org/10.18764/2178-2865.v25n1p11-25

\footnotetext{
1 Jornalista. Doutora em Comunicação pela Universidad Autónoma de Barcelona (Espanha). Professora colaboradora de Publicidade na Escola Superior de Relaciones Públicas, da Universidad de Barcelona. E-mail: alinemartinsm@gmail.com

2 Psicóloga. Mestre em Sociologia pela Universidade Federal de Alagoas (UFAL). Doutoranda em Lógica e Filosofía da Ciência pela Universidade de Salamanca e psicóloga do Instituto Federal de Alagoas (IFAL). Email: annajuliagiurizatto@gmail.com

${ }^{3}$ Assistente Social. Doutora em Jornalismo e Ciência da Comunicação pela Universidade Autônoma de Barcelona(UAB). Professora do Programa de Pós-graduação em Serviço Social da Universidade Federal de Alagoas(PPGSS/UFAL). Email: elvira.barretto@fsso.ufal.br

${ }^{4}$ Advogado, Especialista em Filosofia e História pelo Centro Universitário Estadual - UNINTER, pequisador vinculado ao CNPQ no grupo de estudos Gênero e Direitos Humanos do Serviço Social da Universidade Federal de Alagoas - UFAL, Email: jota1235@gmail.com
} 


\section{INTRODUÇÃO}

O presente texto convida a uma reflexão acerca do agravamento da violência de gênero em tempo de pandemia da Covid-19, com um espectro de abordagem em âmbito nacional e internacional. Ao tomar a violência de gênero como questão central deste texto, adota-se a perspectiva feminista de gênero (SAFFIOTI, 2004; SCOTT, 1990; BUTLER, 2001) por oferecer como categoria de análise 0 pré-requisito da historicidade na apreensão da problemática, no sentido de neutralizar a crença de que os homens nascem naturalmente mais violentos do que a mulher. Trata-se de conceber o alastramento de uma violência demarcada pela condição de ser mulher - e de todas suas implicações simbólicas e normativas inscritas na estruturação identitária do ser feminino tradicional em relação com a estruturação identitária do ser masculino tradicional, implicando relações de poder herdeiras da cultura patriarcal e androcêntrica.

A perspectiva de organização social que adota o masculino como ideal do humano e a opressão às mulheres, presente neste modelo, fazem parte da história social da construção dos gêneros, passando por distintas épocas, desde a antiguidade grega até os dias de hoje. Para refletir sobre a violência de gênero na atualidade, propomos uma narrativa que se encadeia a partir de elos de compreensão de que raízes da cultura da violência em sociedades capitalistas ocidentais, herdeiras da tradição judaico-cristã e patriarcal ${ }^{1}$,se retroalimentam para dar suporte à manutenção da ordem burguesa moderna ${ }^{2}$, com parâmetros em um modelo referencial de organização socioideológica e político-econômica, a do homem (gênero), branco colonizador (raça/etnia), burguês (classe social) e heterossexual.

A constituição de uma ordem social com esses parâmetros traz intrinsecamente uma cultura de violência expressa de várias formas, como por exemplo, a violência de gênero. A correlação da violência com a condição de gênero e o desenvolvimento de áreas de pesquisa e de categorias sociológicas específicas sobre o tema levaram à construção de expressões distintas, com implicações empíricas e teóricas diferentes. Mesmo com a diversidade de tipologias, há sentidos equivalentes nas distintas nominações: violência de gênero, violência contra a mulher, violência doméstica, violência familiar, violência conjugal (BANDEIRA, 2014). Importante destacar que mesmo que sob diferentes expressões, elas têm sido utilizadas pelas várias correntes teóricas, ordenamentos jurídicos, organizações da sociedade e movimentos feministas para indicar a centralidade que as ações violentas incidem contra a mulher.

Neste trabalho, adota-se o termo violência de gênero, embora sejam utilizados referenciais que seguem outras denominações. A escolha do termo violência de gênero parte da premissa de que homem (macho da espécie humana) não é "naturalmente" mais violento do que a mulher (fêmea da 
espécie humana) e que as concepções de feminino e masculino estão demarcadas por um processo sócio-histórico. Embora em constante construção, o processo de ressignificação da ordem tradicional de gênero não tem eliminado os padrões androcêntricos e patriarcais presentes nas relações domésticas e institucionais.

Com o necessário isolamento social em decorrência da pandemia da Covid-19, vê-se que a violência de gênero tem ganhado muita repercussão. 0 recente olhar inquietante para esse problema antigo pode indicar mudanças importantes no trato com a temática e levanta algumas problematizações importantes sobre as causas da violência de gênero. Neste sentido, é fundamental refutar as interpretações equivocadas acerca da pandemia como responsável pelo aumento do fenômeno, pois tal afirmativa nega a historicidade da violência de gênero, permeada pelo longo processo desigual de relações de poder e pela estrutura patriarcal e androcêntrica que acompanha as dinâmicas de gênero presentes e agravadas em período de crise, como durante a pandemia da Covid19.

Definidos os termos, segue-se com a pretensão de apresentar 0 panorama do agravamento da violência de gênero no contexto pandêmico da Covid-19, compreendendo que esse feito poderá contribuir para desvelar a urgência do enfrentamento da violência de gênero, cuja crise de convivência social e de risco para as mulheres preexiste à pandemia. A demonstração da gravidade de tal problemática sugere a possibilidade de desvelamento de caminhos para o enfrentamento da bárbara realidade que acomete as mulheres em escala global e aponta a necessidade de compreender como se configura essa questão na realidade brasileira, na qual as desigualdades e violências são estruturantes e perpassam o ordenamento de gênero, raça a classe da sociedade.

\section{O MUNDO EM CRISE SANITÁRIA E A PANDEMIA DA VIOLÊNCIA DE GÊNERO}

É comum o pensar de que existe uma correlação entre o desenvolvimento de um país e a seriedade com a qual a violência de gênero é tratada; entretanto, a realidade não confirma esta hipótese quando se constata que o desenvolvimento estritamente econômico não necessariamente implica um desenvolvimento social, em particular no que concerne à superação da violência na convivência social.

Os países nórdicos da Europa possuem algumas das legislações mais avançadas sobre questões de igualdade de gênero, não obstante mantêm mitos e estereótipos que favorecem a impunidade dos agressores sexuais. Segundo o relatório da Anistia Internacional divulgado em 2019, apesar de figurar entre os primeiros países do mundo no tocante à igualdade de gênero, Dinamarca, Finlândia, Noruega e Suécia possuem elevados índices de estupro, e seus sistemas de justiça falham 
no que se refere às sobreviventes de violência sexual. A persistência de mitos sobre o que é ou não uma violação e os estereótipos de gênero são, segundo os/as autores/as do estudo, os que provocam esse alarmante paradoxo. Entre os mitos está o de responsabilizar a vítima pelos abusos sofridos, a falsa percepção de que estupros ocorrem principalmente por estranhos ou que apenas um tipo de homem pode ser considerado estuprador.

Recentemente, como já se supunha, a situação da violência de gênero em países desenvolvidos foi agravada com a crise sanitária mundial. Não seria difícil, assim, especular sobre os desdobramentos igualmente preocupantes nos países que não possuem o mesmo desenvolvimento socioeconômico. Cabe mencionar que, mundialmente, a estatística sempre foi alarmante: uma em cada três mulheres sofre violência física ou sexual durante a vida, de acordo com a Organização Mundial da Saúde (OMS, 2019), o que vem a ser a violência "mais difundida, mas entre as menos relatadas violações dos direitos humanos".

O confinamento, a forma mais eficazpara reduzir o número de contágios da Covid-19, também evidenciou a realidade de mulheres e meninas que sofrem violência de gênero e que durante este período de quarentena precisaram estar trancadas com seu agressor. 0 desafio de superar o vírus potencializou um foco de vulnerabilidade e pôs em xeque a necessidade de reforçar os mecanismos de proteção num momento de maior instabilidade emocional, financeira e física.

Como bem abordou a ONU Mulheres, fatores como restrições de movimento ou quarentena geraram obstáculos adicionais para fugir de situações violentas ou ter acesso a serviços essenciais. Na Argentina, Canadá, França, Alemanha, Espanha, Reino Unido e Estados Unidos, autoridades governamentais, pessoas que defendem os direitos das mulheres e aliadas da sociedade civil relataram um aumento de queixas de violência doméstica durante a crise e aumento da necessidade de proteção de emergência (BRADLEY; TAUB, 2020; THOMPSON, 2020).

É nesse contexto que as estatísticas têm muito a dizer e ilustrar a inquietante impotência presente nos desdobramentos do isolamento de mulheres e meninas em companhia de seus parceiros violentos, controladores e tiranos, separando-as das pessoas e dos recursos que podem ajudá-las. São ilustrativos alguns referentes retratados pela mídia para demonstrar como a crise agravou a violência de gênero em alguns países da Europa, América Latina, Estados Unidos e China.

Em maio de 2020, num momento em que Europa havia deixado de ser o epicentro da pandemia no mundo, a FIFA (Federação Internacional de Futebol), a Organização Mundial de Saúde e a Comissão Europeia se uniram para lançar a campanha \#SafeHome, ou lar seguro, para apoiar mulheres e crianças em risco de violência doméstica. A campanha foi uma resposta conjunta das três instituições aos recentes picos nos relatos de violência doméstica nos países europeus. 


\section{AGRAVAMENTO DA VIOLÊNCIA DE GÊNERO NO CONTEXTO DA PANDEMIA DA Covid-19}

De acordo com a agência de notícias Euronews (2020), os dados sobre violência de gênero não são coletados sistematicamente. No entanto, há números que conformam a ideia do panorama internacional. Na Itália, o Ministério do Interior registrou onze assassinatos em onze semanas de confinamento. Na Espanha, conforme escreveu Del Bosque (2020), a Delegação do governo contra a violência de gênero noticiou que o telefone 016 , de atenção às vítimas de violência de gênero, havia recebido 295 consultas em abril de 2020, enquanto 43 foram registradas no mesmo período de 2019 , ou seja, $586 \%$ a mais no ano da pandemia. Na França, o ministro do Interior Christophe Castaner revelou, no final de março, que a violência de gênero havia aumentado em 30\% desde o início do confinamento no país, em 17 de março de 2020.

No Reino Unido, a situação parece ainda mais alarmante, segundo uma reportagem do Bradley e Taub (2020) para o New York Times, durante o primeiro mês após o início do bloqueio, 16 mulheres e meninas foram mortas em suspeitos homicídios domésticos - mais do que o triplo do número do mesmo período de 2019. Pelo menos mais dez morreram nos dois meses seguidos. A mais velha delas tinha 82 anos de idade. A mais nova, morta ao lado de sua mãe e da irmã de 4 anos, tinha 2 anos. Segundo o artigo, o governo britânico não destinou mais fundos para estratégias de combate à violência de gênero e proteção às vítimas durante a pandemia e os resultados só ratificam isso.

Diante da crise, muitos governos, incluindo os nórdicos, se mobilizaram para responder a essa ameaça crescente. Em alguns países europeus, como a França, as farmácias se tornaram um ponto de encontro. As vítimas podiam usar o código "máscara 19" para pedir ajuda aos farmacêuticos. O mesmo serviço foi implantado na Espanha, na Alemanha e na Noruega. A farmácia, um recurso essencial de saúde aberto durante a temporada de confinamento, virou um bom aliado. Também são disponibilizados na Europa um serviço de SMS e outras linhas de apoio que permitem às vítimas pedir ajuda.

$\mathrm{Na}$ Europa, se está acelerando a negociação dos marcos legais, melhorando as leis da polícia e aumentando os serviços de atenção às mulheres. Trinta e quatro estados membros do Conselho da Europa ratificaram a Convenção de Istambul ${ }^{3}$, que recebeu uma lista completa de medidas para proteger as mulheres, com especial atenção aos possíveis efeitos a longo prazo da pandemia no equilíbrio entre a vida profissional e pessoal, e a independência econômica das mulheres.

No contexto latino-americano, a pandemia do coronavírus também agravou a violência doméstica e os feminicídios, além de interromper as pautas feministas de cada país. Na Argentina, segundo Pont (2020), onde o movimento \#niunamenos completou 5 anos, foram registradas entre $1^{\circ} \mathrm{de}$ janeiro e 30 de maio, 140 mortes violentas de mulheres. Nesse país, o Ministério das Mulheres, Géneros e Diversidades informou que em abril de 2020, com a quarentena, foi registrado um aumento de $39 \%$ nas consultas por violência de gênero. 
Já no Peru, a campanha \#MáscaraVioleta foi lançada pelo Programa das Nações Unidas para o Desenvolvimento (PNUD) como parte da iniciativa "no estás sola", que realiza em conjunto com - Ministério das Mulheres e Populações Vulneráveis, e a Agência Espanhola de Cooperação Internacional para o Desenvolvimento (AECID). As máscaras de cor violeta viraram um símbolo de luta, solidariedade e compromisso para acabar com a violência machista no país que em 8 semanas de quarentena, teve 12 feminicídios e 226 estupros. Destes últimos, segundo Colombo (2020), 132 foram contra meninas menores de idade e o número representa o dobro em comparação a 2019.

De acordo com Gupta (2020), em março, manifestantes no México e em outros países se uniram contra o feminicídio. No México, muitas mulheres ficaram em casa e fizeram uma greve para chamar a atenção às 1.006 mulheres mortas no país em 2019. Nesse país, o serviço de atenção telefônica para casos de violência de gênero registrou aumento de $80 \%$. A Bolívia, segundo Colombo (2020), é o país com mais casos de violência doméstica na América do Sul. Foram assassinadas 9 mulheres apenas no período entre 21 de março e 21 de maio, representando um número $20 \%$ maior do que o mesmo período no ano passado. 0 relatório da Comissão Econômica para a América Latina e 0 Caribe afirmou que, no contexto do agravamento da crise econômica que afetará a região no póspandemia, as mulheres devem ser as mais atingidas (NAÇÕES UNIDAS, 2020).

Nos EUA, uma em cada três mulheres sofreu estupro, violência física e/ou perseguição por um parceiro íntimo (definido como cônjuge ou parceiro atual ou antigo) em sua vida, de acordo com uma pesquisa de 2010 do Centers for Disease Controland Prevention (2010). E nos últimos anos, o número de casos de violência doméstica (que inclui violência por parceiros íntimos e familiares) aumentou, representando cerca de $20 \%$ de todos os crimes violentos nos EUA em 2018, de acordo com o Departamento de Justiça. Segundo Godin (2020), no país que chegou ao número de 50 mil pessoas infectadas por dia com o coronavírus, o centro de atenção National Domestic Violence Hotline relatou um número crescente de mulheres que informavam que seus agressores estavam usando a Covid-19 como um meio de isolá-las ainda mais de seus amigos e familiares.

De acordo com Bosman (2020), o Departamento de Polícia de Chicago informou que as ligações relacionadas à violência doméstica aumentaram $12 \%$ desde o início do ano até meados de abril, em comparação com o mesmo período de 2019. Em outras cidades, incluindo Los Angeles e Nova York, a polícia viu uma queda nas ligações, mas as autoridades informaram acreditar que as vítimas estavam tão próximas de seus agressores que não conseguiram chamar a polícia.

A violência doméstica também é um problema generalizado na China. De acordo com uma pesquisa realizada em novembro de 2016, pela Federação de Mulheres da China, 30\% das mulheres chinesas casadas sofreram alguma forma de violência doméstica (ALLEN-EBRAHIMIAN, 2020). 


\section{AGRAVAMENTO DA VIOLÊNCIA DE GÊNERO NO CONTEXTO DA PANDEMIA DA Covid-19}

No país onde a Covid-19 foi descoberta, em dezembro de 2019, o número de casos de violência doméstica relatados à polícia local triplicou em fevereiro em relação ao ano anterior, segundo o site de notícias Allen-Ebrahimian (2020). Autoridades atribuem ao confinamento o desencadeador desses casos. Embora a violência por parceiro íntimo possa inicialmente parecer não relacionada à Covid-19, uma delegacia na China recebeu 162 denúncias de violência doméstica em fevereiro de 2020. No ano anterior, a delegacia recebeu apenas 47. Os principais defensores da violência "antidoméstica" atribuem esse aumento nos casos relatados à quarentena. Dados de cenários impactados por crises humanitárias indicam que a violência por parceiro íntimo é altamente prevalente e a vulnerabilidade das mulheres a essa violência aumenta durante estados de emergência (ALLENEBRAHIMIAN, 2020). Cabe mencionar que a China aprovou sua primeira lei de violência doméstica em 2016, depois de anos de pressões e negociações realizada por ativistas.

Quando se volta para o Brasil, depara-se com o desastroso lugar de epicentro da pandemia da Covid-19. Em um país em que 13 mulheres são assassinadas diariamente (BRASIL, 2019), e que 1 a cada 10 mulheres nordestinas relatam ter sofrido ao menos um episódio de violência doméstica nos últimos 12 meses (CAMPOS, 2017), a prerrogativa do isolamento social para conter a quarentena expõe a mulher a risco de vida, quando convivem com parceiros atores de agressão, em um contexto em que se reduz 0 acesso aos serviços de proteção social.

Os dados iniciais indicam que a real situação das mulheres brasileiras durante a pandemia é preocupante. De acordo com os dados fornecidos pela Secretaria de Segurança de São Paulo, divulgados em 15 de abril de 2020, os assassinatos de mulheres em casa dobraram nessa cidade durante a quarentena (BARBOSA et al., 2020). Em âmbito nacional, a quantidade de denúncias de violência contra a mulher recebidas no canal 180 cresceu quase $9 \%$ durante a quarentena, segundo dados do Ministério da Mulher, da Família e dos Direitos Humanos (BRASIL, 2020b).

O Fórum Brasileiro de Segurança Pública, a pedido do Banco Mundial (que tem revelado preocupação com a situação da violência contra mulheres no país), produziu uma pesquisa com alguns estados da federação acerca da situação de violência sofrida pelas mulheres brasileiras durante 0 período de pandemia. Embora os dados se mostrem frágeis, do ponto de vista de revelarem toda a multiplicidade e magnitude da violência contra a mulher, indicam que o feminicídio aumentou em quase todos os estados da federação pesquisados, dez respectivamente, e se mantendo estável em apenas dois estados (BRASIL, 2020a). Entretanto, diante das dificuldades em produzir essas informações, estes números podem ser ainda maiores.

De acordo com a pesquisa, em vários estados há dificuldade da Polícia Militar em computar dados de violência de gênero, como no Rio Grande do Sul, em que apenas em abril de 2020, após a solicitação do Fórum Brasileiro de Segurança Pública, foi criada uma rubrica/filtro para 
qualificar a violência doméstica nos dados produzidos acerca dos casos acompanhados pela Brigada Militar. A diminuição das denúncias também é citada como dificuldade a ser enfrentada durante a pandemia, "uma vez que em função do isolamento muitas mulheres não têm conseguido sair de casa para fazê-la ou têm medo de realizá-la pela aproximação do parceiro" (BRASIL, 2020a, p3).

Segundo o documento, no mês de abril, o número de Medidas Protetivas de Urgência e de registro de boletim de ocorrência, que geralmente dependem da presença física das vítimas, reduziram, com exceção do Rio Grande do Norte, localidade em que o decreto que impôs a quarentena no Estado é do dia 1 de abril (BRASIL, 2020a). Vale salientar que a subnotificação, um dos problemas conhecidos e estudados nas situações de violência doméstica no Brasil, possivelmente tem se acentuado no período de isolamento pela pandemia.

Outro fator que precisa ser evidenciado é a redução de recursos para lidar com a violência de gênero, pois parte desta verba tem sido direcionada às demandas da pandemia. Goulart (2020) cita que o maior serviço de atendimento a mulheres vítimas de violência sexual do país, o Hospital Pérola Byington (SP) foi fechado, sendo reaberto depois de um tempo em decorrência de pressão popular. A ONU Mulheres tem se posicionado diante deste tema, apontando que as mulheres e meninas podem sofrer obstáculos adicionais para fugir de situações violentas ou acessar ordens e serviços essenciais de proteção para salvar suas vidas, devido a fatores como cortes orçamentários e restrições ao movimento em quarentena. Desta forma, a Organização vem orientando os governos a fazer da prevenção e reparação da violência contra as mulheres como parte essencial de seus planos nacionais de resposta à Covid-19, com medidas a serem incorporadas nos pacotes de apoio econômico (ONU MULHERES, 2020).

No Brasil, um possível agravante para esta situação é o cenário de flexibilização da posse e do porte de armas de fogo no país. De acordo com pesquisas realizadas pelo IPEA (2019), entre 2012 e 2017 houve o aumento de $28,7 \%$ de homicídios contra mulheres praticado com armas de fogo dentro do domicílio (BRASIL, 2019). Esta realidade que já vem se acentuando na sociedade brasileira pode ser ainda mais severa em contexto de pandemia, na qual as mulheres e outros grupos mais vulnerabilizados socialmente, tendem a ser mais afetados pela crise.

A oportunidade conduz a evidenciar a particularidade do estado de Alagoas e constatar 0 aumento significativo de casos de violência de gênero, segundo registros da Patrulha Maria da Penha $(\mathrm{PMP})^{4}$, órgão do governo estadual que trabalha junto ao Judiciário na proteção das vítimas de violência doméstica. Conforme registro na instituição, neste ano de 2020 já foram realizadas 242 intervenções da Força Tarefa (FT) quando acionadas pelo Disque 1905 , resultando em 25 prisões até 0 mês de junho. Nota-se que houve aumento considerável se comparado com todo o ano de 2019 que se registra apenas 8 prisões. Outro registro importante é que no ano de 2019, 158 mulheres foram 
acompanhadas pela PMP. Em 2020, até o momento, estão sendo acompanhadas 399 mulheres, mais que 0 dobro.

Um dado relevante do estado e que contrasta com os dados nacionais é o aumento no número de Medidas Protetivas de Urgência. Com base em registros dos arquivos da PMP, entre os meses de janeiro a maio de 2020 , houve um aumento de $146 \%$ no número de medidas protetivas se comparadas ao mesmo período do ano anterior. Embora indique o aumento das situações de violência de gênero em Alagoas, a maior emissão desta Medida reflete um trato diferenciado com a questão, que pode contribuir com possibilidades de proteção da vítima. Conforme relatado neste artigo, a Medida Protetiva de Urgência geralmente depende da presença física da vítima. Em Alagoas, a Ordem dos Advogados do Brasil Seccional Alagoas (OAB-AL) solicitou, e foi acatada pelo Tribunal de Justiça de Alagoas (TJAL), a emissão de uma recomendação para que os juízes prorrogassem as medidas protetivas de urgência às mulheres em situação de violência doméstica. Com essa prerrogativa a Patrulha Maria da Penha passou atuar com base em um panorama que se gravou com o isolamento social

Em cenário nacional, para lidar com essa situação de violência, o governo criou 0 aplicativo "Direitos Humanos Brasil", disponível no site do Ministério da Mulher, da Família e dos Direitos Humanos. A Secretaria de Segurança Pública de alguns estados disponibilizou o boletim de ocorrência por via eletrônica para vítimas de violência doméstica, o que tem permitido que as vítimas façam registro da ocorrência pela internet, sem precisar se deslocar a uma delegacia. Iniciativas implementadas pela sociedade civil, Ongs e instituições privadas também têm contribuído para o enfrentamento da violência doméstica no período de pandemia (BRASIL, 2020a).

Entretanto, estas são iniciativas pontuais. O problema da violência doméstica contra a mulher requer compreensão da ordem de gênero que perpassa a produção das violências e a elaboração de ações coordenadas, articuladas em nível nacional e com diversos dispositivos que ofereçam apoio jurídico e socioassistencial às vítimas. 0 agravante desta problemática, circunscrita pela pandemia, exige um olhar cuidadoso para o tema e para a situação em que se encontram as mulheres brasileiras, com investimento em pesquisa e com fortalecimento das políticas públicas e redes de apoio.

\section{ALGUMAS CONSIDERAÇÕES}

A menina com medo faz um furo no escuro com a ponta do dedo Cai um pingo de luz Amanhece 
Diante de tantos desafios, é notável a importância de pesquisas de organizações feministas sobre a vida das mulheres na crise sanitária, onde é possível ver que o tema da violência de gênero se expressa em contexto mais amplo de desigualdades sociais preexistentes à pandemia. Nessa direção, a Sempreviva Organização Feminista (SOF), traz reflexões significativas quando traz subsídios para a compreensão real da dinâmica da vida das mulheres na crise pandêmica, por meio da pesquisa Sem Parar: o trabalho e a vida das mulheres na pandemia.

Nessa pesquisa fica claramente evidenciada a intensificação e o aprofundamento da desigualdade vivenciada pelas mulheres brasileiras como expressão da violência estrutural. Entre outros importantes aspectos salienta-se que $50 \%$ das mulheres brasileiras passaram a cuidar de alguém na pandemia. Aparentemente, esse dado poderia ser apreendido na sua expressão fenomênica, mas é mais profundo e complexo, conforme evidencia Sempreviva Organização Feminista(SOF,2020), o cuidado é, inequivocadamente, o centro da sustentabilidade da vida, pois

Não se trata de um problema a ser resolvido, nem de uma demanda a ser absorvida pelo mercado. Trata-se de uma dimensão da vida que não pode ser regida pelas dinâmicas sociais pautadas no acúmulo de renda e de privilégios. Não deu certo até aqui sendo assim. A organização do cuidado ancorada principalmente na exploração do trabalho de mulheres negras e no trabalho não remunerado das mulheres é um fracasso retumbante para a busca de redução das desigualdades antes e durante a pandemia do coronavírus.(SOF,2020,p.11).

Quanto à violência contra as mulheres, é uma realidade imprescritível nesse contexto, onde na "intimidade do lar" estão presentes as relações de poder, tanto quanto as formas de controle e desqualificação das mulheres. Outro aspecto evidenciado com o resultado da pesquisa é que há interligação entre a violência psicológica e a manutenção da responsabilização das mulheres por garantir a sustentação das casas e o bem-estar das pessoas que delas dependem. Nesse sentido, a promoção de autonomia das mulheres, não somente do ponto de vista material, é de suma importância para o enfrentamento da violência de gênero, assim,

[...] a promoção da autonomia das mulheres é chave no desafio de integrar essas conexões das ações e políticas de enfrentamento a violência. A visibilidade dos trabalhos domésticos e de cuidados, essenciais para a sustentabilidade da vida, precisa ter como consequência política uma agenda que vá além do reconhecimento, e avance para que estes trabalhos sejam reorganizados, valorizados, redistribuídos. Para enfrentar a intensificação da sobrecarga com o trabalho doméstico e de cuidado, demonstrada pela pesquisa, são necessárias políticas orientadas a transformações estruturais. Não se trata apenas de uma negociação no interior de cada domicílio, muito menos de normalizar dinâmicas de terceirização e externalização, que reforçam a precariedade da vida e do trabalho de mulheres negras, deixando intactos $e$ inquestionáveis os mecanismos de desresponsabilização do Estado, dos homens e do conjunto da sociedade com essas atividades que são essenciais para a sustentabilidade da vida. (SOF,2020, p.52). 


\section{AGRAVAMENTO DA VIOLÊNCIA DE GÊNERO NO CONTEXTO DA PANDEMIA DA Covid-19}

Em suma, nesta reta final fica claro o alastramento, em esfera global, de uma triste experiência humana chamada violência de gênero. É muito comum, considerando o contexto pandêmico da atualidade, o uso da expressão pandemia para tudo que representa algo negativo na vida e que tem uma larga extensão de acometimento, no mundo. Inclusive no texto foi usada a expressão: "a pandemia da violência de gênero".

Aprofundando os termos, vê-se que é adotada a concepção de que a violência de gênero é uma pandemia e, se pandemia é uma enfermidade transitória amplamente disseminada então, é muito positivo conceber a violência de gênero como uma pandemia, pois estaremos afirmando que a problemática tem um caráter transitório. Reconhecendo a transitoriedade da violência de gênero na vida humana, a reconhecendo como pandemia, pressupõe-se uma coerência teórica e epistemológica, de acordo com o marco teórico de abordagem do referido tema na presente reflexão que finda.

O panorama da violência de gênero no mundo, em tempos de pandemia, espelha e revela a dimensão e a gravidade da problemática que ceifa a vida de milhares de mulheres e tornam criminosos milhares de homens. Isso não pode ser tratado de forma natural. As estatísticas demonstram que não gera impacto produtivo o investimento massivo no âmbito da justiça e da segurança. É uma problemática de cunho social e histórico que tem raízes nas normatizações de gênero que instigam os homens (macho da espécie humana) a serem violentos, como valor positivo no processo de socialização destes, desde a infância. É, portanto, imprescindível o investimento em revisões paradigmáticas na educação e nas distintas formas de expressão cultural em âmbito global, levando em conta que o cuidado é centro da sustentabilidade da vida.

A título de últimas reflexões cabe reconhecer que vivemos em um estado de descuido global entre humanos, com enraizado sentimento de ódio gerado pelo medo da fragilidade, da vulnerabilidade que constitui esse sujeito chamado humano. No contexto capitalista moderno que se sustenta na educação regida pela cultura patriarcal e androcêntrica, fomenta-se o descuido e proliferase fragilidades, vulnerabilidades que assustam a versão masculina tradicional do macho da espécie humana. Assim, o ocidente segue pelo século XXI, acreditando que a barbárie das guerras e o ódio do século passado seriam parte de uma história que não se repetiria. A realidade ensina o contrário, as guerras e o ódio, o desejo de ser proprietário de bens e pessoas são reconfigurados em escala global e adentra o mundo da vida privada e íntima (BARRETTO, 2008).

Ratifica-se que o estágio de descuido, de ódio, de violência, de perda de valores éticos e do relativismo moral, da indiferença cúmplice, que se alastra no mundo está relacionado à ordem patriarcal de gênero, androcêntrica, classista, uma vez que o homem (modelo tradicional) se sente ameaçado quando é despertado de sua fragilidade e a mulher (modelo não tradicional) por causar 
incerteza no exercício de sua liberdade, se instala, portanto, a condição ideal da prática da violência de gênero.

Em termos mais amplos, entendemos que à medida que mulheres ou homens incorporam um novo modo de ser feminino ou masculino, os seus modos de ser tendem a causar um tensionamento nos modos de ser tradicionais de homens e mulheres. Com isso emerge a incerteza para estes e, assim, despertam-se as fragilidades. É neste despertar que surge o sentimento de ódio, violência e evidencia-se o perigo do descuido entre humanos,

Bem, se vivemos em uma cultura em que os principais valores positivos para uma pessoa a ser reconhecida são baseados nos princípios do capitalismo, isto é, do poder de consumo e acumulação de riqueza, do poder sobre o outro inferiorizado pela sociedade, então quando surgem os obstáculos para que esses valores sejam cumpridos, o que vai acontecer? A tendência é que o princípio da violência ofereça "grandes ideias" para que se livrem da dor.

Deduz-se, portanto, que o sentimento de medo da própria fragilidade tem sua origem na ordem simbólica patriarcal estruturante do "arquétipo viril" e nas normas de gênero. Este é o patamar basilar da cultura de violência que dá suporte à pandemia da violência de gênero que se agrava com a pandemia da Covid-19. Em sendo a violência de gênero uma pandemia, a seu fim ou atenuação, é possível: "[...] cai um pingo de luz. Amanhece".

\section{REFERÊNCIAS}

ALLEN- EBRAHIMIAN, B. China'sdomesticviolenceepidemic.Axios. 07 de março de 2020. Disponível em: https://www.axios.com/china-domestic-violence-coronavirus-quarantine-7b00c3ba-35bc-4d16-afddb76ecfb28882.html. Acesso em: 3 jul. 2020.

AMNESTY INTERNACIONAL. Europe: time for change: justice for rape survivors in the nordic countries. Disponível em: https://www.amnesty.org/en/documents/eur01/0089/2019/en/. 3 de abrilde2019, Index number: EUR 01/0089/2019. Acesso em: 28 jun. 2020.

BANDEIRA, L. M. Violência de gênero: A construção de um campo teórico e de investigação. Sociedade e Estado, v. 29, n. 2, p. 449-469, maio, 2014.

BARBOSA, J. P. M. et al. Interseccionalidade e outros olhares sobre a violência contra a mulher em tempos de pandemia pela Covid-19. Scielo em Perspectiva, 2020.

BARRETTO, Elvira Simões. Identidades de Género en las series de televisión: una reflexión en torno a la Cultura de la Violencia. Barcelona-Espanha, 2008. 398p. Tese doutoral do Programa de Doctorat "Periodisme i Ciències de laComunicació".

BAUMAN, Zigmunt. Vida líquida. Rio de Janeiro, Zahar, 2007. 
BOSMAN, J. Domestic Violence Calls Mount as Restrictions Linger: 'No One Can Leave'. 15 de maio de 2020. Disponível em: https://www.nytimes.com/2020/05/15/us/domestic-violencecoronavirus.html. Acesso em: 3 jul. 2020.

BRADLEY, J; TAUB, A. As Domestic Abuse Rises U.K. failings leave victims in peril. 02 de julho de 2020. Disponível em: https://www.nytimes.com/interactive/2020/07/02/world/europe/uk-coronavirusdomestic-abuse.html. Acesso em: 3 jul. 2020.

BRASIL. Fórum Brasileiro de Segurança Pública. Violência doméstica durante a pandemia de Covid-19. 2020a.

BRASIL. Instituto de Pesquisa Econômica Aplicada; Fórum Brasileiro de segurança Pública. Atlas da Violência. Brasília, Rio de Janeiro, São Paulo, 2019.

BRASIL. Ministério da Mulher, da Família e dos Direitos Humanos. Coronavirus: sobe o número de ligações para canal de denúncia de violência doméstica na quarentena. 2020b. Disponível em: https://www.gov.br/mdh/pt-br/assuntos/noticias/todas-as-noticias/2020-2/marco/coronavirus-sobe-onumero-de-ligacoes-para-canal-de-denuncia-de-violencia-domestica-na-quarentena. Acesso em: 1 jul. 2020.

BRASIL. Instituto de Pesquisa Econômica Aplicada; Fórum Brasileiro de segurança Pública. Atlas da Violência. Brasília, Rio de Janeiro, São Paulo, 2019.

BUTLER, Judith. El Género en disputa. Buenos Aires, Paidós, 2001.

CAMPOS, C. H. DE. Lei Maria da Penha: necessidade de um novo giro paradigmático. Revista Brasileira de Segurança Pública, v. 11, n. 1, p. 10-22, 2017.

COLOMBO, S. Pandemia aumenta violência de gênero e adia pautas feministas na América Latina. 03 de junho de 2020. Disponível em: https://www1.folha.uol.com.br/mundo/2020/06/pandemiaaumenta-violencia-de-genero-e-adia-pautas-feministas-na-america-latina.shtml. Acesso em: 3 jul. 2020.

COUNCIL OF EUROPE. Conveção de Istambul. Ação contra a violência contra a mulher e a violência doméstica. Disponível em: https://www.coe.int/en/web/istanbul-convention. Acesso em: 1 jun. 2020.

DEL BOSQUE, Marisa. Menos mujeres asesinadas durante el confinamiento, pero más en riesgo de serlo. 10 de maio de 2020. Disponível em:

https://www.elmundo.es/yodona/lifestyle/2020/05/19/5ec3ac0121efa0ae5f8b4606.html. Acesso em: 3 jul. 2020.

FIFA, European Commission and World Health Organization launch \#SafeHome campaign to support those at risk from domestic violence. World Health Organization. 26Maio 2020. Disponível em: https://www.who.int/news-room/detail/26-05-2020-fifa-european-commission-and-world-healthorganization-launch-safehome-campaign-to-support-those-at-risk-from-domestic-violence. Acesso em: 28 jun. 2020.

GENTILI, Pablo. Três teses sobre a relação trabalho e educação em tempos neoliberais. In: LOMBARDI, J.; SAVIANI, D. \& SANFELICE, J. (orgs.). Capitalismo, trabalho e educação. Campinas, SP: Autores Associados, HISTEDBR, 2002. 
GODIN, M. As Cities Around the World Go on Lockdown, Victims of Domestic Violence Look for a Way Out. Time, 18 de março de 2020. Disponível em: https://time.com/5803887/coronavirusdomestic-violence-victims. Acesso em: 27 jun. 2020.

GOULART, D. Notas sobre uma leitura feminista da pandemia. Le Monde Diplomatique Brasil, 31 mar. 2020. Acervo Online. Acesso: 23 jun. 2020.

GUPTA, J. What does coronavirusmean for violenceagainstwomen?Women's Media Centre, 19 de março de 2020. Disponível em: https://womensmediacenter.com/news-features/what-does-coronavirusmean-for-violence-against-women. Acesso em: 28 jun. 2020.

HEILBORN, Maria Luzia. Família em processos contemporâneos: inovações culturais na sociedade brasileira.São Paulo,Loyola, 1995.

NAÇÕES UNIDAS. La pandemia del Covid-19 profundiza la crisis de los cuidados en América Latina y el Caribe. [s.l: s.n.]. Disponível em: https://estadisticas.cepal.org/cepalstat/Portada.html. Acesso em: 1 jul. 2020.

ONU MULHERES. Violência contra as mulheres e meninas é pandemia invisível, afirma diretora executiva da ONU Mulheres - ONU Mulheres. Disponível em:

http://www.onumulheres.org.br/noticias/violencia-contra-as-mulheres-e-meninas-e-pandemia-invisivelafirma-diretora-executiva-da-onu-mulheres/. Acesso em: 3 jul. 2020.

PONT, E.La violencia contra las mujeres: la consecuencia invisible de la pandemia.La Vanguardia. 04 de junho de 2020. Disponível em: https://www.lavanguardia.com/vida/juniorreport/20200602/481576160749/violencia-genero-aumenta-coronavirus-pandemia.html. Acesso em: 30 jun. 2020.

SAFIOTTI, Heleieth. Gênero, Patriarcado, Violência. São Paulo, Editora Perseo Abramo, 2004.

SCOTT, J. Joan. Gênero: Uma categoria útil para a análise. Educação e Realidade. Porto Alegre: UFRGS, 1990.

SLATER, Don. Cultura do consumo \& modernidade. São Paulo: Nobel, 2002.

SOF-Sempreviva Organização Feminista. Sem parar:0 trabalho e a vida das mulheres na pandemia. SOF, São Paulo, 2020. Disponivel em: http://mulheresnapandemia.sof.org.br/wpcontent/uploads/2020/08/Relatorio_Pesquisa_SemParar.pdf. Acesso em: 20 dez. 2020.

THOMPSON, R. Violencia contra las mujeres al amparo de la Covid-19. Euronews. 15 de abril de 2020. Disponível em: https://es.euronews.com/2020/04/15/violencia-contra-las-mujeres-al-amparo-dela-Covid-19. Acesso em: 30 jun. 2020.

\section{Notas}

\footnotetext{
${ }^{1}$ Heilborn (1991) postula a existência de um eixo organizador das sociedades herdeiras da cultura judaico-cristã, que é o complexo simbólico honra-vergonha, que subsidia o senso comum com a ideia de prestígio e extremado poder masculinos, cujo exercício está na centralidade da moral e controle femininos.
} 
2 Esta já traz na sua lógica uma violência intrínseca - a exploração entre seres humanos, para extração da mais-valia -, hoje complexificada com o estágio financeiro globalizado do capital, com a expansão mundial da cultura do consumo, no reconhecimento do sujeito (o ser) a partir do ter bens simbolicamente valorizados na economia das aparências (BAUMAN, 2007; GENTILI, 2002; SLATER, 2002).

${ }^{3}$ A Convenção do Conselho da Europa para a Prevenção e o Combate à Violência Contra as Mulheres e a Violência Doméstica, ou Convenção de Istambul é uma convenção do Conselho da Europa destinada a combater a violência contra mulheres e a violência doméstica através da prevenção da violência, proteção das vítimas e eliminação da impunidade dos agressores. A convenção foi aberta a assinaturas em 11 de maio de 2011, em Istambul. Em junho de 2017, a convenção tinha sido ratificada por 44 países e pela União Europeia(COUNCIL OF EUROPE, 2020).

${ }^{4}$ Dados dos arquivos da Patrulha Maria da Penha, disponibilizados para a presente pesquisa.

${ }^{5}$ O telefone 190 é um Disque Denúncia destinado a atender urgências e emergências policiais. 